\title{
Chapter 13 \\ Preliminary Study on Electron Spin \\ Resonance Dosimetry Using Affected \\ Cattle Teeth Due to the Fukushima Daiichi \\ Nuclear Power Plant Accident
}

\author{
Kazuhiko Inoue, Ichiro Yamaguchi, and Masahiro Natsuhori
}

\begin{abstract}
To validate radiation dose of cattle affected by the Fukushima Daiichi Nuclear Power Plant (FNPP) accident, we applied electron spin resonance (ESR) tooth dosimetry. Teeth were collected from cattle that had stayed continuously after the accident in Okuma Town within the ex-evacuation zone of the FNPP accident. Radiation exposure to cattle attributed to the FNPP accident was confirmed retrospectively by X-band ESR tooth dosimetry, which was almost consistent with the estimated radiation dose from airborne and individual cattle, whereas positive radiation-induced signals (RIS) were not detectable in any sample by nondestructive measurement using L-band ESR tooth dosimetry. Although ESR tooth dosimetry reflects total radiation doses of affected animals, the uncertainty of measurement was relatively large. Therefore, in order to accurately measure the additional radiation dose from the nuclear accident, it is necessary to clarify possible causes of the uncertainty. Making continuous improvements, X-band ESR tooth dosimetry for animals in the ex-evacuation zone is ongoing.
\end{abstract}

Keywords ESR tooth dosimetry $\cdot$ L-band $\cdot$ X-band $\cdot$ Cattle $\cdot$ Fukushima Daiichi Nuclear Power Plant · Nuclear disaster

\footnotetext{
K. Inoue $(\varangle)$

Department of Translational Research, Tsurumi Dental University,

Yokohama, Japan

e-mail: qb6k-inue@asahi-net.or.jp

I. Yamaguchi

Department of Environmental Health, National Institute of Public Health,

Wako, Saitama, Japan

M. Natsuhori

School of Veterinary Medicine, Kitasato University, Towada, Aomori, Japan
} 


\subsection{Introduction}

Electron spin resonance (ESR) tooth dosimetry is an established method of evaluating radiation dose by measuring stable unpaired electrons produced by radiation exposure in a tooth $[1,2]$. Ionizing radiation generates radicals proportionate to absorbed dose depending on radiation quality and energy. These radicals react rapidly and disappear in the most part of our body due to water, but in organized matrices without water, they can persist indefinitely. This phenomenon has been recognized in bones and teeth and has been shown to be a promising method for retrospective dosimetry, based on free radicals being stabilized in the hydroxyl apatite matrix in tooth enamel (Fig. 13.1). It has been confirmed that mean detection limit is $205 \mathrm{mGy}$, ranging from 56 to $649 \mathrm{mGy}$ at the fourth International Comparison [3]. Using extracted teeth, X-band ESR tooth dosimetry has been applied to retrospective dose assessment of atomic bomb survivors of Hiroshima and Nagasaki (Hibakusha) [4, 5], the Chernobyl Nuclear Power Plant (CNPP) accident [6], nuclear bomb tests [7], and radiological accidents [8-10]. An "ideal" ESR spectrum with some parameters is shown in Fig. 13.2. The peak-to-peak amplitude " $\mathrm{A}$ " is the first derivative of the resonance microwave absorption. The peak-to-peak linewidth, " $\Delta \mathrm{B}$," is related to the modulation frequency that is important for controlling the signal-to-noise ratio. The resonance field "Br" indicates the natural resonance frequency of the radical species due to the Zeeman effect. The dose obtained with ESR dosimetry is well correlated with the standard method such as hematology-based

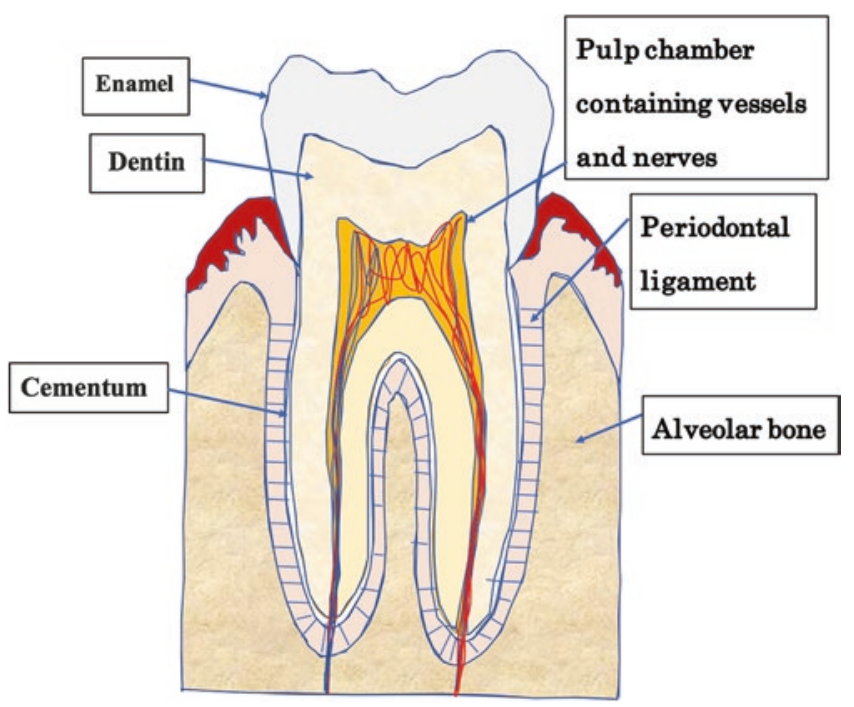

Fig. 13.1 Anatomy of a tooth and locations of tooth tissues 


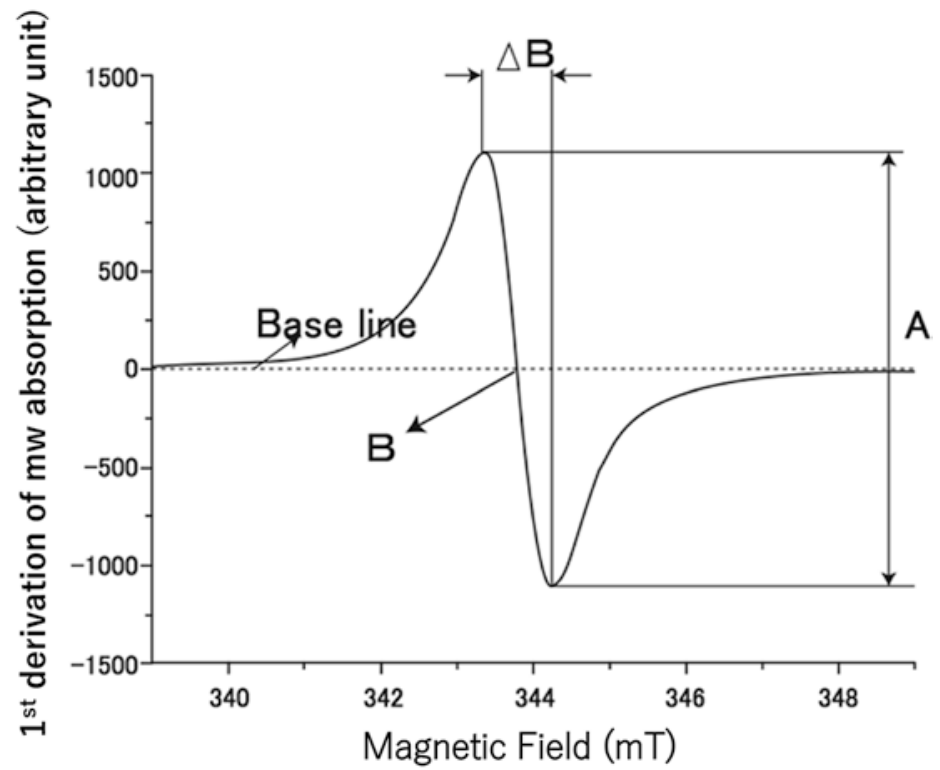

Fig. 13.2 "Ideal" ESR spectrum with illustrations of some its parameters. (Original: International Atomic Energy Agency. Use of electron paramagnetic resonance dosimetry with tooth enamel for retrospective dose assessment. IAEA Vienna IAEA-TECDOC-1331 (2002). https://www-pub. iaea.org/MTCD/Publications/PDF/te_1331_web.pdf)

assays [11]. Those dosimetry studies are carried out at conventional ESR frequencies called X-band of the electromagnetic spectrum (e.g., $9 \mathrm{GHz}$ ) so that the method is called X-band ESR tooth dosimetry. This X-band ESR has high sensitivity for dose estimation using the extracted or deciduous teeth. ESR spectra of tooth enamel after exposure to different doses are shown in Fig. 13.3.

With a radiation emergency in mind, an L-band ESR apparatus has been developed for in situ measurement as triage using teeth in the mouth as indices [12]. This method is available for retrospective dose assessment and for triage when workers are involved in an accident that caused radiation exposure such as a nuclear disaster or a large-scale radiation exposure accident [13].

ESR tooth dosimetry is a method of evaluating the accumulated radiation dose and is thought to be applicable for animals affected by the FNPP accident, which is crucial for studying the biological effect of persistent low-dose-rate (LDR) radiation [14-16]. The FNPP accident affected animals and several environmental study groups started research activities on livestock. We have been analyzing the influence of radiation exposure on affected cattle since September 2012. We have carried out dose estimation using information of environmental monitoring and radioactivity deposition density on the ground. We have collected 50 cattle at Okuma Farm in Okuma Town, Fukushima Prefecture (Fig. 13.4). Research of the radiation effect on large animals is still a challenging topic. To obtain scientific results, it is essential to 


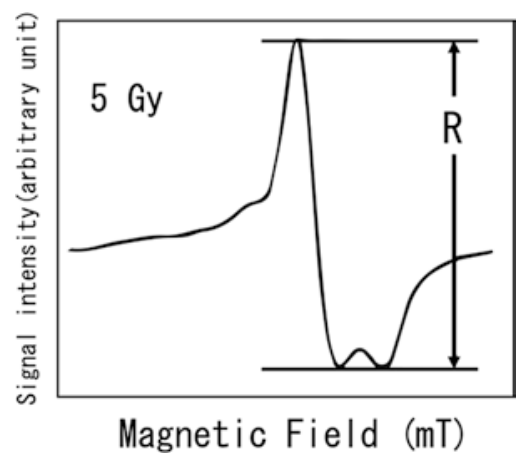

Fig. 13.3 ESR spectra of tooth enamel after 5Gy irradiation. The dosimetric component of the spectrum after irradiation with $5 \mathrm{~Gy}$ is shown in this chart. $\mathrm{R}$ is the peak-to-peak amplitude used for ESR dose reconstruction. (Original: International Atomic Energy Agency. Use of electron paramagnetic resonance dosimetry with tooth enamel for retrospective dose assessment. IAEA Vienna IAEA-TECDOC-1331 (2002). https://www-pub.iaea.org/MTCD/Publications/PDF/ te_1331_web.pdf)

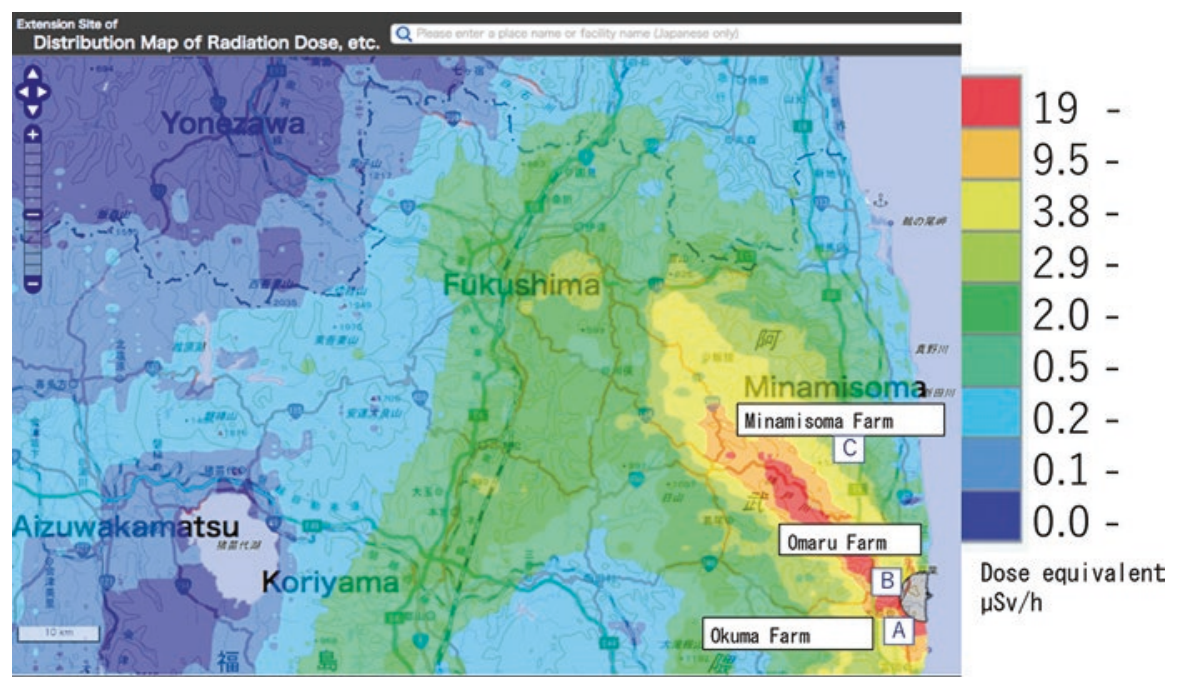

Fig. 13.4 Radiation dose-rate map obtained by airborne monitoring results and the location of Okuma Farm as of May 31, 2012. This map was quoted from the website provided by Nuclear Regulation Authority, Japan. Dose rate shows $\mu \mathrm{Sv} / \mathrm{h}$ as a dose equivalent rate including background radiation. (http://ramap.jaea.go.jp/map/)

estimate radiation dose accurately for discussing the dose response. In order to validate ESR tooth dosimetry, we estimated dose of cattle affected by the FNPP accident using ESR and compared the dose with that estimated using monitoring tendency data. 


\subsection{Material and Methods}

\subsubsection{Sample Collection}

Teeth were collected from cattle that had continued to stay in Okuma Farm, that is located in the ex-evacuation zone of the FNPP accident (Fig. 13.4). Dissection of cattle was performed on May 14, 2017. Table 13.1 shows information on cattle whose radiation dose was measured in this study.

\subsubsection{Nondestructive Measurement Using L-Band ESR Spectroscopy}

For the comparison of the L-band ESR response among different energy photons, we used two standard materials. One was a standard tooth irradiated by the cesium-137 $\left({ }^{137} \mathrm{Cs}\right)$ source provided from the ESR Center for the Study of Viable Systems at Dartmouth, NH, USA. The other was a tooth sample exposed to $20 \mathrm{~Gy}$ of X-rays in an X-ray irradiator (MBR-1505R2, Hitachi Medical, Tokyo, Japan) at $150 \mathrm{kV}$ and $1 \mathrm{~mA}$, with $0.1-\mathrm{mm}$ copper plus 0.3 -mm aluminum filtering. This X-ray irradiation gives a response about 4 times as large as $\gamma$-rays from ${ }^{137} \mathrm{Cs}$.

In order to adjust for variations in the measured radiation-induced signal (RIS) amplitude that result from instrumental instability and/or external environmental factors, the ratio of differentiated voltage as a radiation-induced signal to the differentiated voltage of 4-oxo-2,2,6,6,-tetramethylpiperidine-d16-1- ${ }^{15} \mathrm{~N}$-1-oxyl $\left({ }^{15} \mathrm{~N}\right.$ PDT) for each measurement was calculated and normalized to the same ratio in the standard tooth exposed to $20 \mathrm{~Gy}$ of $150 \mathrm{kV}$ X-ray as described above.

After extracting from the jawbone portion of each cattle, a maxillary incisor tooth was washed with tap water. Then with a design knife, as much soft tissue as possible was removed and the labial side was used for the measurement surface by L-band ESR tooth dosimetry. The ESR spectrum was acquired using standard measurement parameters such as 20 scans, including a scan range of $2.5 \mathrm{mT}$, a scan time of $3 \mathrm{sec}$, and a modulation amplitude of $0.4 \mathrm{mT}$ [17]. This process was repeated 3 times. A plastic tube containing a solution of ${ }^{15} \mathrm{~N}$-PDT was fixed in a position in close proximity to the surface loop and used as a reference of positive standard. Spectra from each of the collected datasets were analyzed using non-linear leastsquares fitting to estimate the peak-to-peak signal amplitudes of the radiation-induced signals and of ${ }^{15} \mathrm{~N}$-PDT. RIS and signals of ${ }^{15} \mathrm{~N}$-PDT were then averaged to provide the mean amplitude for each tooth and at each dose.

Table 13.1 Basic

characteristics of each cattle and estimated radiation dose

\begin{tabular}{l|l|l|l}
\hline Cattle & Ear tag ID & Sex & Birth date \\
\hline A-1 & $12416-04378$ & Female & $2006 / 12 / 26$ \\
\hline A-2 & $12425-47537$ & Female & $2007 / 9 / 2$ \\
\hline A-3 & $08597-08639$ & Female & $2012 / 6 / 1$ \\
\hline
\end{tabular}




\subsubsection{Destructive Measurement by X-Band ESR Spectroscopy}

The enamel portion on the labial side of the cattle teeth was taken out by a nipper about $3 \mathrm{~mm}$ in size, taking care not to contain dentin, and was used as a sample for X-band ESR spectroscopy after grinding in an agate mortar to a size of $1 \mathrm{~mm}$ in diameter so as to enter a sample tube. ESR spectra were acquired using parameters of 40 scans, including a scan range of $5 \mathrm{mT}$, a scan time of $30 \mathrm{sec}$ and a modulation amplitude of $0.2 \mathrm{mT}$ power of $2 \mathrm{~mW}$, and a time constant of $0.03 \mathrm{~s}$. This process was repeated for a total of five datasets at each dose.

\subsubsection{Measurement of Radioactivity Concentration}

Radioactive concentrations of Cs and strontium-90 $\left({ }^{90} \mathrm{Sr}\right)$ in the molar of Cattle A-3 were measured. For radioactive $\mathrm{Cs}$, the ashed sample was analyzed by a germanium semiconductor detector (CFG-SV-76, ORTEC, TN, USA). Sr-90 was extracted by the ion exchange method and analyzed by a low-background beta-ray measuring device after achieving radioactive equilibrium with yttrium-90 (Y-90). In principle, measurement was performed for $3,600 \mathrm{sec}$, and the radioactivity concentration was calculated.

\subsubsection{Data and Statistical Analysis}

Data analysis was carried out using code developed by Ivannikov [18]. Statistical analysis was performed using R3.3.1 [19]. Radiation dose of each sample was determined by the additive dose-response method assuming a linear dose-response of the ESR signals to additional irradiated doses of each sample. This method employs step-by-step irradiation to each sample additionally. Absorbed dose is estimated by a linear regression analysis [2].

\subsection{Results}

\subsubsection{Dose Estimation by Dose-Rate Monitoring Using Survey Meters}

Cumulative radiation dose based on ambient monitoring using an air chamber survey meter during 6 years since March 2011 was estimated to be 270 mGy [20]. 


\subsubsection{Dose Estimation by Radiation Dose Monitoring Using Individual Dosimeters}

Radiation dose measured by an individual dosimeter attached to representative cattle from December 2013 to December 1, 2017 was 57 mGy (Fig. 13.5). Considering weathering, total dose from the day the FNPP accident happened to the start of monitoring was calculated from deposition density of iodine-131 $\left({ }^{131} \mathrm{I}\right)$, tellurium$132\left({ }^{132} \mathrm{Te}\right),{ }^{132} \mathrm{I},{ }^{134} \mathrm{Cs}$ and ${ }^{137} \mathrm{Cs}$ on the ground immediately after the accident [21]. Estimated total dose of Cattle A-1 and A-2 from March 2011 was 160 mGy. Similarly total dose of Cattle A-2 calculated was 67 mGy after adjusting deposition density of radionuclides to its birth month.

\subsubsection{Dose Estimation by ESR Tooth Dosimetry}

Positive RIS were not detectable in any cattle sample examined by nondestructive measurement using L-band ESR dosimetry (Fig. 13.6). For comparison, an exposed human tooth is shown in Fig. 13.7. In this spectrum, RIS were detected between 0.7 and $1.1 \mathrm{mT}$.

A representative X-band ESR tooth spectroscopy of Cattle A-1 is shown in Fig. 13.8. The additive-dose-response for radiation dose estimation is shown in Fig. 13.9. The dose of this sample is the value of negative $\mathrm{x}$-intercept value, $67 \mathrm{mGy}$. The uncertainty of dose estimation was calculated using the Monte Carlo method by picking up randomly generated parameters 100 times, adapting the model obtained by the additive-dose method. Estimated $95 \%$ confidence interval was between 1.3

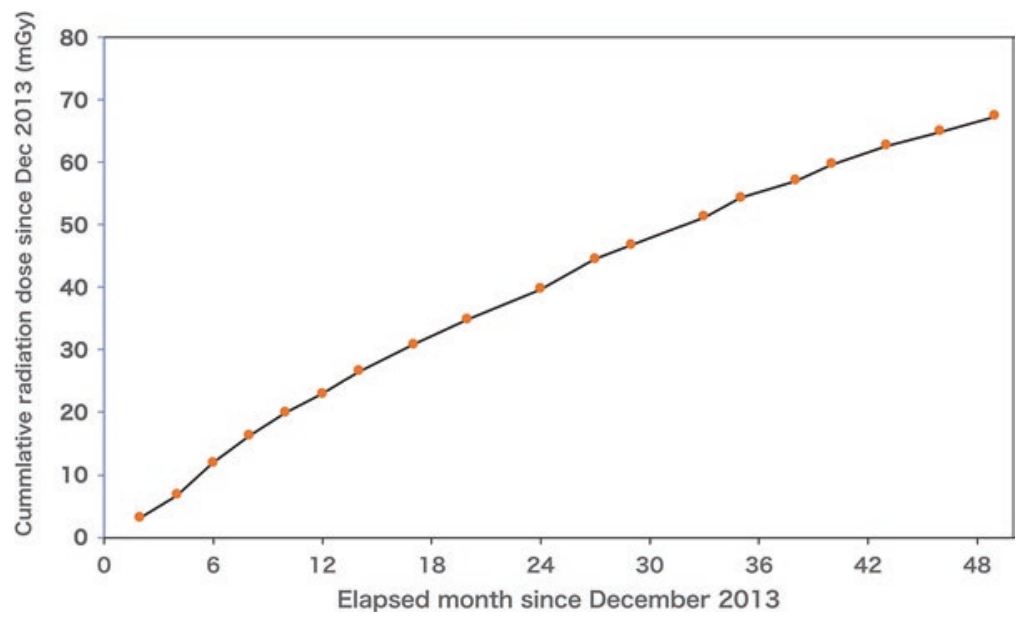

Fig. 13.5 Cumulative radiation doses to cattle monitored by using glass dosimeters since December 2013 


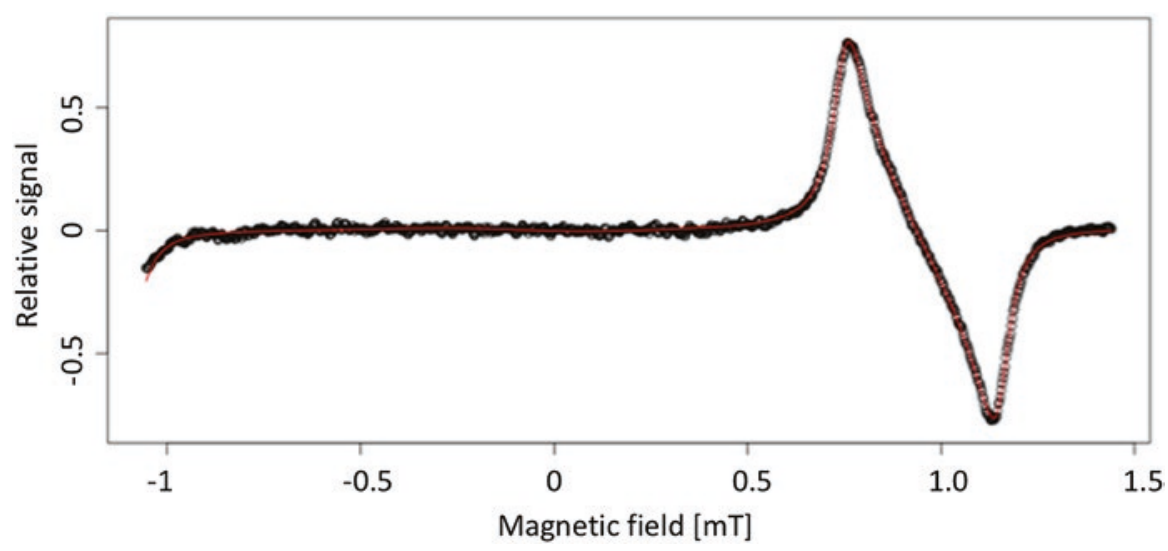

Fig. 13.6 Representative ESR spectrum of a sample of incisors from Cattle A-2 using L-band spectrometry. Measurement condition: 20 scans, scan range of $2.5 \mathrm{mT}$, a scan time of $30 \mathrm{sec}$, a modulation amplitude of $0.4 \mathrm{mT}$. The signal around $0.8-1.2 \mathrm{mT}$ shows a positive reference control of ${ }^{15} \mathrm{~N}-\mathrm{PDT}$

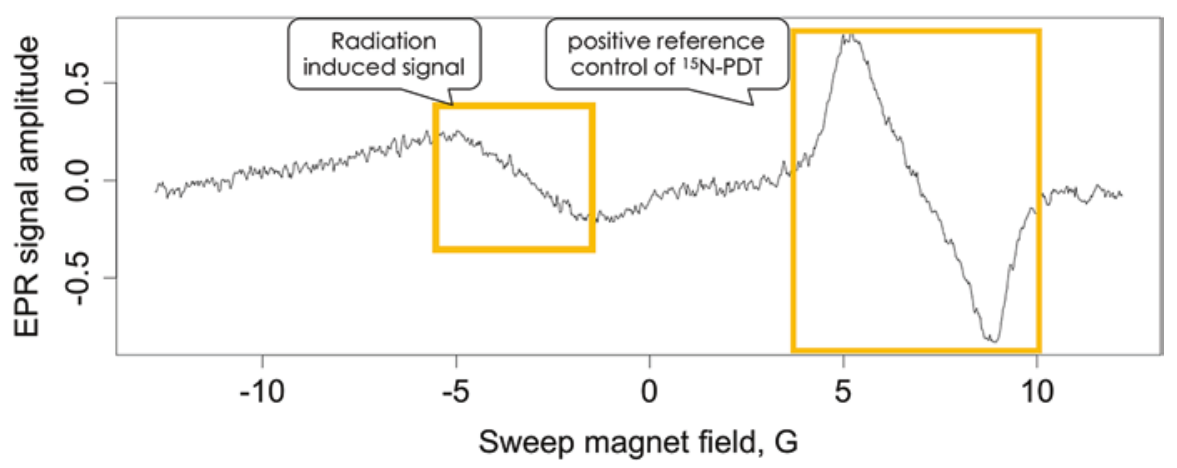

Fig. 13.7 Example of ex vivo ESR spectrum of human tooth using the L-band. This tooth is exposed to 1Gy by X-ray. Measurement condition: 20 scans, scan range of $2.5 \mathrm{mT}$, a scan time of $3 \mathrm{sec}$, a modulation amplitude of $0.4 \mathrm{mT}$. The signal from a positive control is observed around $0.6-0.9 \mathrm{mT}$. Radiation induced signal is observable at $0.5-1 \mathrm{mT}$

and 119 mGy. Total dose estimated by X-band ESR tooth dosimetry was compared with other methods, that is, calculated from ambient dose-rate and from individual monitors after adding the initial estimated dose before December 2013 (Table 13.2). Both estimations using ground-deposited radioactive $\mathrm{Cs}$ and individual monitor were in good agreement. Although the dose range was large, doses estimated by X-band ESR tooth dosimetry of Cattle A-1 and A-3 were not much different from those calculated by other two methods. In Cattle A-2, the dose assessed by X-band ESR tooth dosimetry was eight times the dose assessed by other two methods. 


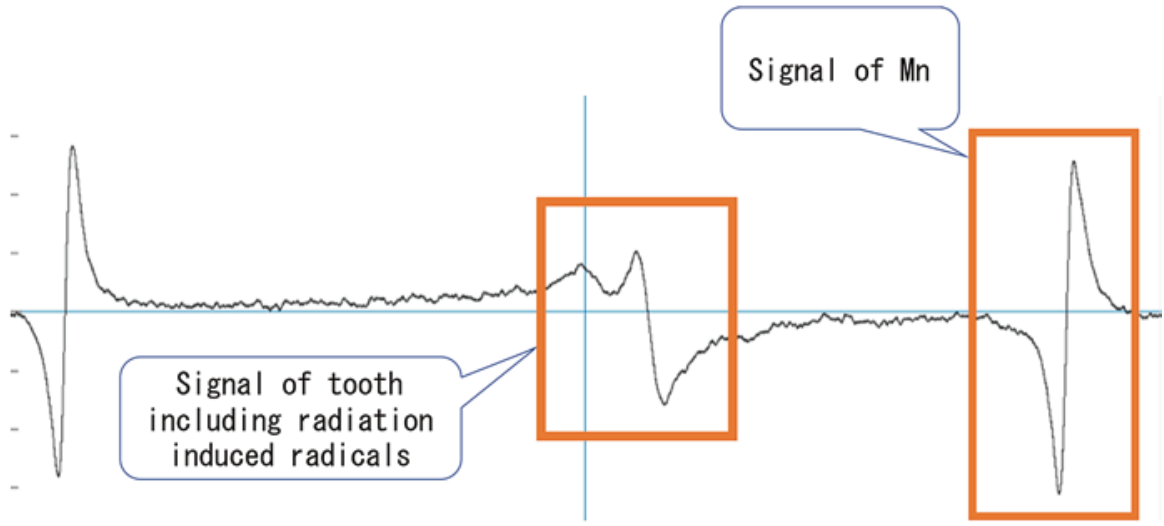

Fig. 13.8 Example of spectrum obtained by X-band ESR tooth dosimetry. In the middle, tooth signals are shown including radiation-induced signal. At both sides, there are standard signals from a Mn marker. The right side is third signal of $\mathrm{Mn}$ and the left side is fourth signal of $\mathrm{Mn}$

\section{(A)}

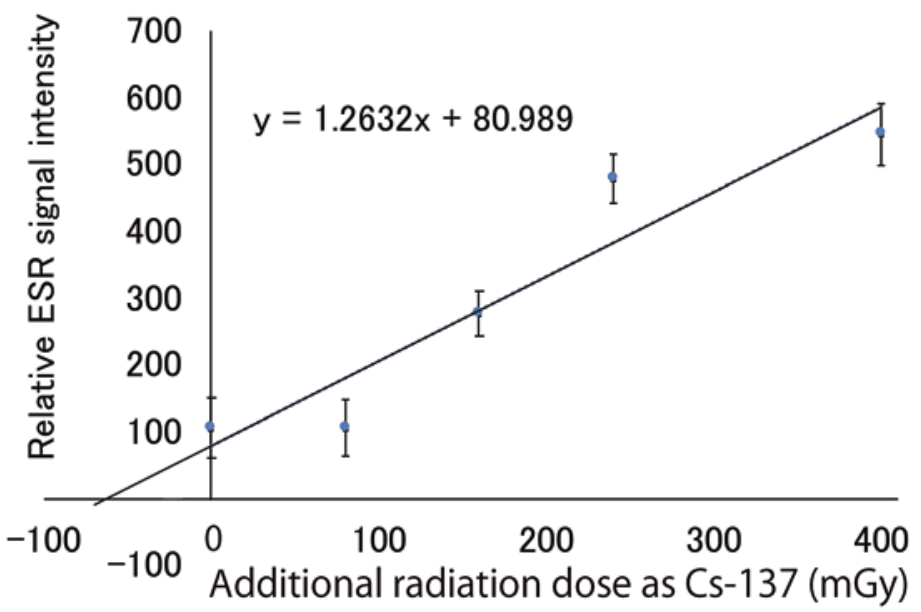

(B)

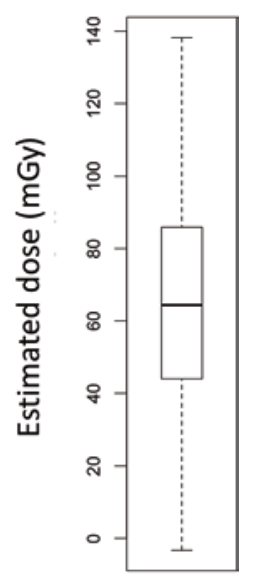

\section{Error bars indicate SD}

Fig. 13.9 Estimated radiation dose of a sample from Cattle A-1 by the additive-dose method. (a) Irradiated dose was converted from $\mathrm{X}$-ray to ${ }^{137} \mathrm{Cs}$ equivalent considering the energy dependency of this ESR tooth dosimetry. Dose is the value of negative $\mathrm{x}$-intercept value, $67 \mathrm{mGy}$. (b) The uncertainty of this dose estimation. The top of the box represents the third quartile and the bottom of the box represents the first quartile. The upper whisker and the lower beard show 1.5 interquartile range. Outliers are plotted as individual points. In this measurement, estimated dose was $67 \pm 30 \mathrm{mGy}$ showing lower value for this cattle 
Table 13.2 Estimated radiation dose [mGy]

\begin{tabular}{l|l|l|l}
\hline Cattle & $\begin{array}{l}\text { Based on initial ground deposition and } \\
\text { ambient dose monitoring }\end{array}$ & $\begin{array}{l}\text { Based on individual dose } \\
\text { assessment }^{\mathrm{a}}\end{array}$ & $\begin{array}{l}\text { ESR range, } \\
\text { median }^{-}\end{array}$ \\
\hline A-1 & 158 & 160 & $37-731,255$ \\
\hline A-2 & 158 & 160 & $1120-1230,1180$ \\
\hline A-3 & 65 & 67 & $114-221,138$ \\
\hline
\end{tabular}

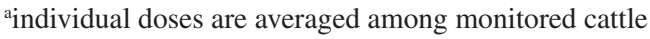

\subsubsection{Radioactivity Concentration in the Molar Tooth of Cattle A-3}

Radionuclides and their concentrations detected in the ashed molar tooth of Cattle A-3 were ${ }^{90} \mathrm{Sr}(46 \pm 2.3 \mathrm{~Bq} \mathrm{~kg}),{ }^{134} \mathrm{Cs}(60.7 \pm 9.9 \mathrm{~Bq} / \mathrm{kg})$, and ${ }^{137} \mathrm{Cs}(60.6 \pm 1.7 \mathrm{~Bq} / \mathrm{kg})$.

\subsection{Discussion}

\subsubsection{Comparisons of Estimated Radiation Dose}

Total dose using X-band ESR tooth dosimetry was 37-1230 mGy. These values are consistent with the estimated radiation dose using monitoring and individual dosimeters, considering that Cattle A-2, who showed had the highest exposure dose, was moved from the higher dose area to Okuma Farm during the 6 years.

\subsubsection{Limitations of ESR Tooth Dosimetry in Regard to Variance and Energy Dependency}

This study tried to measure the actual dose of cattle affected by the FNPP accident using both X-band and L-band ESR tooth dosimetries. Due to its low sensitivity, L-band ESR tooth dosimetry revealed to be not practical for dose assessments associated with the FNPP accident and that the X-band dosimetry can be available with some improvements. Dose of each sample was measured by the additive-dose method. Measurements were performed on each enamel sample individually, taking into account the sample properties and mass. This is because, even with the same tooth, the degree of stable radical generation is affected by the chemical structure of the enamel sample. Response characteristics of thermoluminescence dosimeter (TLD) depend on the mass energy-absorption coefficient of photons and the mass stopping power of charged particles. In dose measurements, energy dependence of ESR dosimetry is relatively similar to TLD. When measuring with animal samples by the additive dose method, the dose response may vary from sample to sample. 
Therefore, it is more desirable to measure separately for each sample. In fact, there is significant variation in dose response of ESR dosimetry among samples of the same boar, especially in older boars [22].

\subsubsection{Effect of External Exposure Due to $\beta$-Particles from Deposited Radionuclides}

Assuming that the deposited density of ${ }^{137} \mathrm{Cs}$ was $1 \mathrm{MBq} / \mathrm{m}^{2}$, external dose-rate of the skin in contact with the ground was estimated to be around $0.14 \mathrm{mGy} / \mathrm{h}$ using coefficient of ICRU report 56 [23]. Assuming $8 \mathrm{~h}$ a day of contact with the ground, the total skin dose from $\beta$-particles for 6 years after the FNPP accident was 1.9 Gy with consideration of weathering. It is a large value in the dose calculation and cannot be ignored. However, this estimated dose was not detectable by ESR tooth dosimetry, indicating that $\beta$-particle exposure to the teeth is negligible unless getting a tooth close to the land.

\subsubsection{Effect of Internal Exposure}

Other concern was a potential impact of internal exposure by radioactive substances inside a tooth and other organs. However, self-absorption dose, that is, radiation dose to a tooth from radionuclides in the same tooth, is limited. It was because of the low concentration of the total radionuclides in tooth, and taking the radioactive strontium as an example, the tooth dose was as low as $2 \mathrm{mGy}$.

\subsubsection{Limitations of ESR Tooth Dosimetry in Regard to the Variance of Background Signals}

The background signal in enamel could be induced by ultraviolet from sunlight [24, 25] or mechanical stimulation during sample preparation [26]. Therefore, further confirmation on the added radiation dose due to the nuclear accident is needed to clarify the attribution of possible causes.

\subsection{Conclusion}

Radiation dose measured by ESR tooth dosimetry reflects the radiation history of each subject. In this study, the dose measured by ESR tooth dosimetry was consistent with the monitored radiation dose. These indicate that teeth can be used 
to assess radiation dose from a radiation accident. However, L-band ESR dosimetry was not sensitive enough to detect the radiation exposure to cattle in Okuma Town.

Acknowledgments The authors are sincerely grateful to the farmers who have donated their precious cattle. Authors also thank Prof. Shin Toyoda and Prof. Harold Swartz for their kind encouragement and valuable suggestions.

This work was in part supported by the Industrial Disease Clinical Research Grants, the Ministry of Health, Labour and Welfare (Grant No. 150803-02), and Grant-in-Aid, Japan Society for the Promotion of Science (JSPS; KAKENHI Grant No. 15 K11435).

\section{References}

1. Brady JM, Aarestad NO, Swartz HM (1968) In vivo dosimetry by electron spin resonance spectroscopy. Health Phys 15(1):43-47

2. IAEA (2002) TECDOC-1331. Use of electron paramagnetic resonance dosimetry with tooth enamel for retrospective dose assessment

3. Fattibenea P, Wieser A, Adolfsson E et al (2011) The 4th international comparison on EPR dosimetry with tooth enamel: Part 1: report on the results. Radiat Meas 46:765-771

4. Nakamura N, Hirai Y, Kodama Y (2012) Gamma-ray and neutron dosimetry by EPR and AMS, using tooth enamel from atomic-bomb survivors: a mini review. Radiat Prot Dosim 149:79-83

5. Ikeya M, Miki T, Kai A, Hoshi M (1986) ESR dosimetry of A-bomb radiation using tooth enamel and granite rocks. Radiat Prot Dosim 17:181-184

6. Chumak VV (2012) The Chernobyl experience in the area of retrospective dosimetry. J Radiol Prot 32:N59-N63

7. Romanyukha A, Schauer DA, Malikov YK (2006) Analysis of current assessments and perspectives of ESR tooth dosimetry for radiation dose reconstruction of the population residing near the Semipalatinsk nuclear test site. J Radiat Res 47(Suppl A):A55-A60

8. Tolstykh EI, Degteva MO, Kozheurov VP et al (2000) Strontium metabolism in teeth and enamel dose assessment: analysis of the Techa River data. Radiat Environ Biophys 39:161-171

9. Trompiera F, Battaglinia P, Bey E (2008) EPR dosimetry in recent radiation accident cases. Radioprotection 43:184

10. Shiraishi K, Iwasaki M, Miyazawa C et al (2002) Dose estimation by ESR on tooth enamel from two workers exposed to radiation due to the JCO accident. J Radiat Res 43:331-335

11. Nakamura N, Miyazawa C, Sawada S et al (1998) A close correlation between electron spin resonance (ESR) dosimetry from tooth enamel and cytogenetic dosimetry from lymphocytes of Hiroshima atomic-bomb survivors. Int J Radiat Biol 73:619-627

12. Miyake M, Liu KJ, Walczak TM, Swartz HM (2000) In vivo EPR dosimetry of accidental exposures to radiation: experimental results indicating the feasibility of practical use in human subjects. Appl Radiat Isot 52:1031-1038

13. Swartz HM, Flood AB, Williams BB et al (2014) Comparison of the needs for biodosimetry for large-scale radiation events for military versus civilian populations. Health Phys 106:755-763

14. Jiao L, Liu ZC, Ding YQ et al (2014) Comparison study of tooth enamel ESR spectra of cows, goats and humans. J Radiat Res 55:1101-1106

15. Toyoda S, Romanyukha A, Hino Y, Itano S et al (2007) Effect of chemical treatment on ESR dosimetry of cow teeth: application to samples from the southern Urals. Radiat Meas 42:1178-1180

16. Zdravkova M, Galleza B, Debuyst R (2005) A comparative in vivo and in vitro L-band EPR study of irradiated rat incisors. Radiat Meas 39:143-148 
17. Yamaguchi I, Sato H, Kawamura $\mathrm{H}$ et al L-band EPR tooth dosimetry for heavy ion irradiation. Radiat Prot Dosim 172:81-86

18. Ivannikov A, Sanin D, Nalapko M et al (2010) Dental enamel EPR dosimetry: comparative testing of the spectra processing methods for determination of radiation-induced signal amplitude. Health Phys 98:345-351

19. R Development Core Team (2005) R: a language and environment for statistical computing. R Foundation for Statistical Computing, Vienna, Austria. ISBN 3-900051-07-0

20. Sasak Ji SH, Deguchi Y et al (2019) Decreased blood cell counts were not observed in cattle living in the "difficult-to-return zone" of the Fukushima nuclear accident. Anim Sci J 90:128-134

21. Natsuhori M, Kojima T, Sato I (2017) Radioactive contamination profiles of soil, external and internal exposure to Japanese Black Cattle after Fukushima Daiichi Nuclear Plant Accident. Jpn J Large Anim Clin 8:143-147

22. Harshman A, Toyoda S, Johnson T (2018) Suitability of Japanese wild boar tooth enamel for use as an electron spin resonance dosimeter. Radiat Measure 116:46-50

23. ICRU (1997) Report 56. Dosimetry of External Beta Rays for Radiation Protection

24. Nakamura N, Katanic JN, Miyazawa C (1998) Contamination from possible solar light exposures in ESR dosimetry using human tooth enamel. J Radiat Res 39:185-191

25. Sholom S, Desrosiers M, Chumak V et al (2010) UV effects in tooth enamel and their possible application in EPR dosimetry with front teeth. Health Phys 98:360-368

26. Aragno D, Fattibene P, Onori S (2001) Mechanically induced EPR signals in tooth enamel. Appl Radiat Isot 55:375-382

Open Access This chapter is licensed under the terms of the Creative Commons Attribution 4.0 International License (http://creativecommons.org/licenses/by/4.0/), which permits use, sharing, adaptation, distribution and reproduction in any medium or format, as long as you give appropriate credit to the original author(s) and the source, provide a link to the Creative Commons license and indicate if changes were made.

The images or other third party material in this chapter are included in the chapter's Creative Commons license, unless indicated otherwise in a credit line to the material. If material is not included in the chapter's Creative Commons license and your intended use is not permitted by statutory regulation or exceeds the permitted use, you will need to obtain permission directly from the copyright holder.

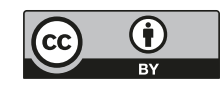

